\title{
Conflictos socioambientales y territoriales en espacios rurales de la comuna de Putaendo (Chile)
}

\author{
Socio-environmental and territorial conflicts in rural spaces of the commune of Putaendo (Chile)
}

\author{
Tomás Palmisano \\ Centro de Estudios Avanzados, Universidad de Playa Ancha, Chile \\ tomaspalmisano@hotmail.com
}

\section{RESUMEN:}

Este artículo explora los conflictos que surgen en torno a la expansión de actividades primario exportadoras. A partir de un estudio de caso en la comuna de Putaendo (Región de Valparaíso, Chile) que combina técnicas cuantitativas y cualitativas, se analiza la dimensión territorial y la socioambiental de las disputas. Tras el análisis se concluye que el avance de la frontera extractiva activa diversas resistencias que, a pesar de su especificidad, están analíticamente imbricadas, como ocurre con las luchas campesinas en torno a los campos cordilleranos y la resistencia popular frente a la gran minería.

Palabras Clave: Territorio, Recursos naturales, Campesinos, Movimiento socioambiental.

\begin{abstract}
:
This article explores the conflicts that arise around the expansion of exporting primary activities. Based on a case study of the Putaendo commune (Region of Valparaíso, Chile) which combines quantitative and qualitative techniques, the territorial and socio-environmental dimensions of the disputes are analysed. The research concludes that the advance of the extractive frontier triggers multiple resistances that, despite their specificity, are analytically intertwined, as occurs with the peasant struggles around the mountain ranges fields and the popular resistance against large-scale mining.
\end{abstract}

KEYWORDS: Territory, Natural resources, Peasants, Socio-environmental movement.

\section{INTRODUCCIÓN}

En las últimas décadas la dinámica del desarrollo capitalista ha priorizado la extracción, circulación y acumulación de recursos naturales/bienes comunes. En la mayoría de los casos, los mismos provienen de los países periféricos, y, dentro de ellos, de regiones que suelen estar distantes de los centros de poder nacional. Existe un nutrido corpus teórico (Alimonda, Toro Pérez y Martín, 2017; Giarracca y Teubal, 2013; Gudynas, 2009; Harvey, 2004; Svampa, 2019; Teubal y Palmisano, 2012; entre otros) que subraya el carácter sistémico de estas tendencias y las nombra como modelo extractivo, neoextractivismo o acumulación por desposesión. La amplitud e intensidad de la avanzada extractivista genera disputas específicas, lo cual ha habilitado nuevas discusiones sobre la conflictividad social y su "enraizamiento" en ámbitos locales. El presente trabajo se inserta dentro de este debate al preguntarse por la manera en que los conflictos territoriales y socioambientales se despliegan y solapan en espacios locales donde se expanden, o proyectan actividades primario exportadoras. Para operacionalizar dicho objetivo nos valemos de un estudio de caso de la comuna de Putaendo (Región de Valparaíso, Chile), a partir del cual nos preguntamos: 1) ¿de qué manera interactúan los diversos elementos presentes en el territorio y qué actores intervienen en los conflictos?; 2) ¿cómo se imbrica el abordaje territorial y socioambiental de las disputas frente a la expansión de actividades extractivas?

La primera pregunta ordenadora del trabajo nos lleva a sentar posición en torno a la noción de territorio, $y$, con ella, a los elementos que la componen. A partir de los aportes de la geografía crítica, entendemos al territorio como el

\section{Recepción: 29 Enero 2020 | Aceptación: 14 Octubre 2020 | Publicación: 01 Diciembre 2020}


espacio apropiado por una determinada relación social que lo produce y lo mantiene a partir de una forma de poder (...) Exactamente porque el territorio posee límites, posee fronteras, es un espacio de conflictualidades (Fernandes, 2005, p. 27. Nuestra traducción).

En este marco, la expansión del capitalismo desencadena procesos de territorialización, desterritorialización y reterritorialización, por los que clases y grupos sociales, instituciones y estado definen sus espacios y territorios de manera divergente a partir de acciones e intencionalidades. El enfrentamiento de estas interpretaciones/acciones antagónicas del territorio supone la existencia constante de conflictualidades, que, como afirma Sobreiro Filho (2017), se explicitan a partir de conflictos específicos que se desatan por el intento de imponer ciertos modelos de desarrollo. Para dar cuenta de estos procesos, Fernandes (2008) sugiere abandonar una mirada monolítica del problema -que acota el territorio a los espacios de gobierno estatal- y enfocarse en la especificidad e interacción de tres tipos de territorio. El primero incluye a los espacios de gobernanza, usualmente vinculados al Estado, que se organizan en diversas escalas (en nuestro caso comunal, provincial, regional, nacional) y contienen a los dos tipos siguientes. El segundo territorio comprende los múltiples tipos de propiedad -en tanto espacio de vida-, ya sean estatales, privadas no capitalistas (individuales, familiares o comunitarias), o capitalistas. Finalmente, existe un tercer territorio "formado por diferentes espacios que son controlados por relaciones de poder. Estos son territorios fluidos o móviles controlados por diferentes sujetos y se producen en los territorios fijos del primero y segundo territorio" (Fernandes, 2008, p. 283. Nuestra traducción).

A esta división analítica se suma el hecho de que el territorio se nos presenta como una totalidad de carácter multidimensional que se conforma a partir de relaciones sociales, económicas, políticas, ambientales y culturales (Fernandes, 2005). En tanto la expansión del capitalismo no se produce de manera unívoca, es posible considerar que en un mismo territorio de primer tipo se expresan múltiples disputas, cuyas intencionalidades privilegian unas dimensiones y escalas por sobre otras. Es allí donde emerge la segunda de nuestras preguntas operacionalizadoras. Dentro del heterogéneo corpus teórico y metodológico sobre el tema (Walter, 2009), consideramos que la ecología política latinoamericana aporta una aproximación enriquecedora para comprender la dimensión socioambiental. Esta perspectiva se focaliza en la politización de la relación naturaleza/sociedad a partir de identificar una distribución y apropiación desigual -en términos geopolíticos y de clase- de los bienes ecosistémicos y de los costos sociales o ambientales intrínsecos de los mismos (Martínez-Alier, 1995). Entonces, el conflicto socioambiental surge cuando se registra la movilización de actores locales -en muchos casos articulados a redes de apoyo nacionales o internacionalescontra los impactos ambientales de una actividad económica específica, un proyecto de infraestructura o un episodio de contaminación (Temper, del Bene y Martínez-Alier, 2015). En estos casos lo ambiental que podríamos entender como el entorno material y simbólico compartido como colectivo- opera como "catalizador" de las disputas.

El diálogo entre saberes académicos y populares impulsado por la ecología política latinoamericana propugnó la incorporación de la noción de territorialidad de la geografía crítica (Bolados, 2016; Moreano, Molina y Bryant, 2017; Toledo López, 2011). Este acercamiento generó tanto un enriquecimiento de los análisis como una superposición conceptual, que en ocasiones suele diluir la capacidad heurística de los aportes. En este trabajo conservaremos la distinción entre conflictos territoriales y socioambientales, aun sabiendo que los mismos pueden superponerse. Por un lado, caracterizaremos como socioambiental a aquel conflicto en que los actores locales ubican en el centro de la querella las transformaciones negativas efectivas o potenciales- de un espacio que se considera común y compartido, muchas veces identificado con el sustantivo naturaleza. De allí que en la mayoría de los casos se problematice una actividad económica específica, un proyecto de infraestructura o un episodio de contaminación. Aunque puede estar involucrado el segundo tipo de territorio Fernandes (2008), la disputa se concentra en el nivel de la gobernanza y de las relaciones sociales que sostienen los modelos de desarrollo en pugna. Por el otro lado, mantendremos la noción de conflicto territorial para caracterizar aquellas disputas en donde uno o varios actores reivindican la 
propiedad y apropiación de un mismo espacio, en coincidencia con el segundo tipo de territorio-propiedad propuesto por Fernandes (2008). En este sentido, se trata de una disputa sobre las fronteras que circunscriben el uso y la gestión de un espacio, una especie de soberanía local. Sostener la mencionada diferenciación conceptual permite no solo identificar más precisamente las dinámicas locales, sino también encontrar momentos de interfaz entre las mismas. Para ello es necesario recurrir a una estrategia que considere dos operaciones específicas: primero, la identificación analítica del objeto de la disputa (cuyos tipos puros serían "territorio-propiedad" y "naturaleza"); segundo, la reconstrucción de la forma en que los propios actores nombran al conflicto, y, a partir de sus narrativas, deben reponerse los núcleos problemáticos que ellos mismos subrayan.

\section{Metodología}

En términos metodológicos este trabajo propone un estudio de caso circunscrito al territorio estatalmente construido como la comuna de Putaendo, ubicada en la provincia de San Felipe de Aconcagua, Región de Valparaíso (ver Figura 1). El área integra la cuenca del río Aconcagua en una zona de transición con diversas elevaciones andinas y sus valles, y tiene un clima mediterráneo semiárido.

Esta investigación de carácter mixto se basó en dos grupos de datos abordados con técnicas diversas. En primer lugar, se realizó una lectura analítica de fuentes secundarias, tales como textos académicos, documentos, estadísticas, sentencias judiciales, mapas, declaraciones, infografías y prensa gráfica, que fueron seleccionadas a partir de su relevancia teórico-empírica con el caso estudiado. Estas fuentes escritas o dibujadas fueron trabajadas como huella no solo de los acontecimientos, sino también de la forma particular en que fueron expresados o narrados. Lo escrito se nos presenta como lo reiterable más allá del destinatario primero y la intención de su producción (que en el caso de esta investigación se buscará reconstruir). Ricouer (2008) afirma que la escritura fija lo dicho del habla, y esa es su principal ventaja. Sin embargo, la fijación que posibilita la escritura -o el dibujo en el caso de los mapas- está también atravesada por la forma particular que tienen esos registros, el estilo al que la narración está sujeta, e incluso los soportes en que se inscriben las huellas de los acontecimientos. En este sentido, aquellas referencias que serán nuestras fuentes llevarán la marca de lo dado (la lengua, las visiones del mundo, acontecimientos, etc.), pero también de lo creado en el momento del registro.

En segundo lugar, contamos con 25 entrevistas en profundidad en las que intervinieron 31 personas, y cuyos detalles se encuentran en un anexo al final del artículo. Las mismas fueron realizadas en 3 visitas a terreno durante 2019 (agosto, septiembre y diciembre) y de ellas participaron agricultores, ganaderos, técnicos, funcionarios estatales, y miembros de organizaciones socioambientales. A las mismas se le aplicó un "análisis cualitativo de contenido" acorde a la propuesta de Mayring (2000). Como complemento de las entrevistas tienen particular importancia las notas etnográficas tomadas en las visitas a Putaendo, pues en ellas pudimos registrar diversas marcas en el territorio, tales como murales, carteles, distribuciones espaciales de las poblaciones, instalaciones e infraestructura.

Ambos soportes no fueron considerados como mera "evidencia" de los acontecimientos, conflictos y tensiones, sino como lugares y momentos donde encontrar huellas de las disputas territoriales y socioambientales en Putaendo. En este sentido, las fuentes primarias y secundarias sirvieron para triangular distintos matices de la conflictividad y proponer algunas líneas interpretativas de sus manifestaciones contemporáneas. 


\section{LA PENETRACIÓN DEL MODELO EXTRACTIVO EN LA COMUNA}

La expansión de las actividades primario exportadoras ha sido un fenómeno registrado a lo largo del Sur global, pero ha adquirido características específicas en cada escala en donde se produce. En el caso de Chile, ello implicó, según cálculos propios a partir de datos de la Comisión Económica para América Latina y el Caribe (CEPAL), un crecimiento del 331,9\% en el monto de exportaciones primarias entre los 1990 y 2017. A pesar de los intentos de diversificación, los productos exportados se centraron en el cobre y sus derivados (alrededor del $50 \%$ ), la pesca (entre el 7 y $8 \%$ ), la madera y subproductos (entre el 4 y el $5 \%$ ), y las frutas y vinos (entre el 3 y 7 \%). Esta expansión de las exportaciones primarias supuso la intensificación de procesos previos gracias a los cambios en las demandas globales o el perfeccionamiento de tecnologías que revalorizaron para el capital territorios que anteriormente eran considerados secundarios. Esta dinámica se materializó a lo largo del país con la aparición o expansión de proyectos de gran minería, cultivos a gran escala y obras de infraestructura que modificaron profundamente el espacio y sus habitantes (De Matheus e Silva, 2016).

Por su propia historia, la comuna de Putaendo configura un caso patente de esta expansión de la frontera extractiva. Hasta mediados del siglo XX, en la zona imperó un sistema de producción asentado en tres grandes fundos (El Tártaro-Lo Vicuña, Piguchén y Bellavista), que controlaban alrededor del $40 \%$ del área regada. Esta tierra era producida por inquilinos - campesinos que pagaban con trabajo (propio o contratado) por la casa y una pequeña porción de tierra del fundo- o medieros (Bengoa, 2015). El $60 \%$ restante de la superficie irrigada se distribuía en más de 3.000 predios de pequeña propiedad (Baraona, Aranda y Santana, 1961). Al control de las tierras regadas las haciendas sumaban la propiedad de alrededor de 110.000 hectáreas (ha) en la cordillera, donde los campesinos llevaban a pastar el ganado de los hacendados y el suyo (ovejas, cabras y vacas) a cambio del pago de derechos de pastaje. En las serranías bajas del sur de la comuna, donde imperaba la pequeña propiedad, la posesión de larga data de los campos de secano permitió a los pequeños ganaderos poseer, e inscribir, las tierras de manera conjunta. Esta estructura agraria fue profundamente modificada por el proceso de reforma agraria que se inició en Chile a mediados del siglo XX. Entre 1967 y 1969 se efectivizó la expropiación de los 3 grandes fundos de Putaendo, y sus tierras (bajo riego y de secano) pasaron ser producidas cooperativamente por 298 familias de ex inquilinos (Corporación de la Reforma Agraria, 1968; García Gatica y Thayer Escalona, 1970). Esta experiencia fue interrumpida con el golpe militar que derrocó a Salvador Allende en 1973 e instauró la dictadura militar encabezada por Augusto Pinochet. El nuevo régimen parceló los asentamientos y asignó, a poco más de 250 familias, una franja de tierra cultivable regada y derechos de pastaje sobre las tierras cordilleranas que se mantuvieron indivisas. Además, con el correr de los años fue impulsándose el reemplazo de los cultivos tradicionales (trigo, alfalfa, legumbres, tabaco y cáñamo) por frutales para el mercado interno, principalmente duraznos, nogales y damascos.

Como veremos más adelante, estos procesos de territorialización, desterritorialización y reterritorialización dejaron importantes marcas en el territorio, que son un factor nodal para explicar la conflictividad territorial y socioambiental contemporánea, y han sido una referencia frecuente en los corpus analizados. Durante varias décadas, la comuna de Putaendo mantuvo cierto carácter periférico a la expansión de las actividades primario exportadoras de gran escala, aunque no fue ajena a la tendencia hacia la concentración y orientación externa de la producción agropecuaria propia del modelo extractivo. Tan es así que, según el último Censo Agropecuario y Forestal disponible, en 2007 había en la comuna 1.071 Explotaciones Agropecuarias (EAP), que ocupaban 124.417,2 ha, de las cuales el 91 \% tenía menos de 20 ha. Ello representó una caída del 31,6 \% respecto al relevamiento anterior realizado en 1997, cuando se contabilizaron 1.565 EAP. En relación a los cultivos, los frutales cubrían, para 2017, 1.980 ha, entre los que el durazno y damasco para mercado interno mantenían una gran importancia (46,61\%), aunque en franco descenso en relación a frutas de exportación como las nueces y la uva de mesa (Larrañaga E. y Osores G., 2017). En paralelo, la actividad ganadera fue disminuyendo. Según un informante clave (Entrevista P23), a inicios de la década de 1990 había cerca de 40.000 animales en la comuna y actualmente quedarían entre 
11.000 y 15.000. Dicho número es similar al registrado en el Censo Agropecuario y Forestal de 2007, que contabilizó 2.013 equinos, 5.121 vacunos y 10.945 caprinos.

$\mathrm{Al}$ incipiente avance de la agroexportación se sumó la gran minería. Si bien existen en la zona yacimientos explotados a pequeña escala -varios de ellos paralizados por agotamiento del mineral, falta de inversión y problemas de escala o regulatorios (Entrevista P12)-, hace poco más de una década la empresa canadiense Los Andes Copper comenzó con las tareas de exploración para la instalación de una mina a cielo abierto. Este proyecto de gran escala, llamado Vizcachitas, se emplaza en el sector de Las Tejas, sobre el lecho del río Rocín (ver Figura 1).

\section{Conflictos SocioterRitoriales y SOcioambientales en la comuna de Putaendo}

El desarrollo de nuestra investigación sobre la conflictividad en la comuna de Putaendo permitió reconocer al menos dos grandes núcleos problemáticos superpuestos en los que se expresan tensiones nuevas y heredadas (estas últimas reconfiguradas a partir de la presión extractiva). Ellos son: 1) la disputa territorial en torno a los campos de cordillera; 2) los conflictos socioambientales que generan los proyectos de gran minería. Para facilitar la comprensión de nuestros argumentos, en la Figura 1 presentamos un mapa que permite "situar" algunos procesos.

Figura 1. Comuna de Putaendo en la actualidad con hitos de las disputas

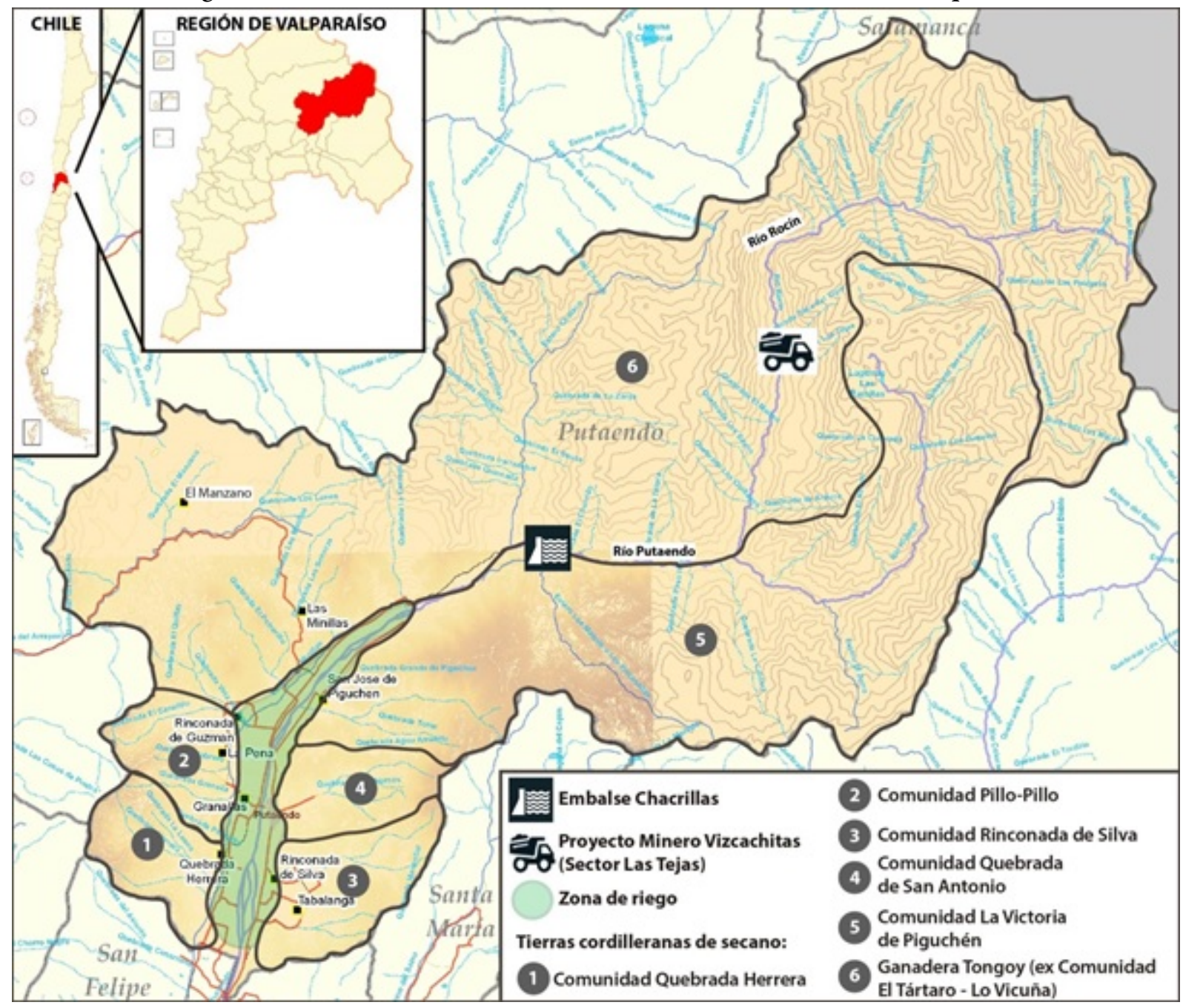

Fuente: Elaboración propia a partir de información de campo sobre mapa de la Biblioteca del Congreso Nacional de Chile. 


\section{LA DISPUTA EN TORNO A LOS CAMPOS DE CORDILLERA}

La desarticulación del proceso de reforma agraria que comenzó con la dictadura de Augusto Pinochet (1973-1990) significó el final de las explotaciones cooperativas estatales y el reparto individual de parcelas (Kay y Pineda, 1998). El tamaño de las parcelas hizo que algunos asentados no pudieran recibir tierras; especialmente fueron castigados los campesinos que habían sido más combativos durante el proceso de reforma agraria. El decreto 208 de 1973 dispuso, entre otros elementos, que: "No podrán postular a la destinación de tierras expropiadas por la Corporación de la Reforma Agraria, los que hubieren ocupado con violencia el predio objeto de la destinación" (Junta de Gobierno de la República, 17 de diciembre de 1973, art. 71 inc. G). Además, la inserción de los campesinos dentro de la lógica mercantil -créditos bancarios, impuestos, canales de comercialización, etc.- se dio con muchísimas dificultades y algunas veces culminó con la venta de las parcelas.

La desterritorialización de la propiedad colectiva campesina impuso la propiedad privada individual en la zona de regadío, pero no logró desarticular completamente la tenencia y aprovechamiento comunal de las zonas de pastoreo. Sin embargo, en la comuna de Putaendo se produjo una importante reconcentración en las tierras cordilleranas que pertenecían colectivamente a los parceleros de El Tártaro-Lo Vicuña (ver Figura 1). Este amplio espacio estaba, y aún está, conformado por un agroecosistema de serranías y elevaciones medias cubiertas parcialmente con vegetación nativa. El mismo carecía de cercas o alambrados que la separasen de los otros predios, como la Comunidad de La Victoria de Piguchén, o incluso con las tierras andinas argentinas, con las que limita al este. Como mencionamos anteriormente, tras el proceso de parcelamiento los campesinos habían obtenido la propiedad y administración colectiva de este territorio. Sus conocimientos sobre las cualidades agroecológicas de la zona y los arreglos necesarios para zanjar las tensiones generadas por la explotación comunitaria les permitieron rápidamente construir una territorialización bajo la figura de la comunidad. En ella cada familia llevaba sus propios animales a las tierras comunales y las dejaba pastando durante gran parte del año. Hacia el otoño, cuando las temperaturas comenzaban a descender, se organizaba una recolección colectiva del ganado (rodeo), que se bajaba a unos corrales de pirca y se distribuía entre los comuneros.

A pesar de conformar tierras de bajo precio de mercado, pocos años después de haber asumido la administración conjunta del predio - como Comunidad de El Tártaro-Lo Vicuña-, sus titulares fueron notificados que las 44.000 ha de secano cordillerano saldrían a remate público por falta de pago de las contribuciones. Este hecho significó un hito en el despojo, que las familias campesinas recuerdan particularmente, ya que representó la emergencia de una nueva territorialidad antagónica a la lograda tras la lucha por la Reforma Agraria. Según los testimonios (Entrevistas P02, P04, P07 y P09), los comuneros habían recolectado y enviado el pago a las oficinas públicas, pero, según las autoridades, este nunca se concretó:

..."Uds. no pagaron los impuestos nosotros [el fisco] le vamos a quitar esa... y la vamos a llevar a remate". Pero para hacer remate tenían que separar esa parte de secano con la parte cultivable, pero nunca se hizo. Y apareció el remate, apareció esta ganadera Tongoy, que nadie la conocía, de la noche a la mañana, el remate nunca fue publicado, nunca se hizo legalmente [... se hizo] en el 78 si no me equivoco (...) en Dictadura, y por lo mismo nadie iba a ir a reclamar porque si no le ponían la pistola en el pecho (Entrevista P02).

La adjudicataria fue la empresa Ganadera Tongoy, una transnacional que compró la tierra con fines especulativos. Así, a mediados de la década de 1980, los campesinos perdieron la propiedad de la cordillera y con ello el control de las formas de uso y de acceso al territorio. La formalidad otorgada por el remate público -y reforzada por la amenaza de la violencia estatal- llevó a que los ganaderos reconocieran al nuevo dueño y comenzaran a pagarle por el talaje de sus animales tal y como lo hacían con el fundo. Si bien aceptaron la nueva situación, en su memoria permaneció el sentido de injusticia de este acto fundacional que se convertiría en una referencia constante de los conflictos territoriales de la comuna. 
Hasta la primera década del siglo XXI la territorialización de la empresa no implicó una puesta en producción directa de las tierras con animales propios. Por el contrario, propugnó una convivencia asimétrica con los ganaderos, que permitió que ellos continuaran aprovechando las pasturas a cambio de un rembolso. Para no perder sus animales, y con ello su forma de vida, los ganaderos aceptaron una serie de acuerdos con Tongoy, que resonaban a la tradicional relación que habían mantenido con el fundo. Este mecanismo solo afectó el área de pasturas de secano, por lo que muchas familias mantuvieron la propiedad de la tierra de regadío. Junto al miedo, la manutención de la tierra irrigada podría explicar por qué el conflicto no escaló en ese momento, pues, de alguna manera, el despojo fue parcial. Los campesinos perdieron la propiedad pero no el acceso- a las pasturas, y continuaron disponiendo de la tierra regada -más fértil y productivaque se dedicaba a la agricultura, la fruticultura o el cultivo de forrajes. En este sentido, durante el período en que la Ganadera mantuvo casi exclusivamente intereses rentísticos sobre la tierra, su territorialización no fue incompatible con la de los crianceros de la comuna. De hecho, en esos años, la empresa impulsó la instalación paulatina de productores caprinos provenientes del norte (Región de Atacama y de Coquimbo), quienes emigraron de sus territorios por la falta de pastos y se instalaron principalmente en el sector de El Manzano y Las Minillas, sin acceso a tierras de regadío (Entrevistas P02, P07, P11 y P23).

Durante varios años se consolidó la relación rentística con el pago del talaje, pero desde 2001 la situación comenzó a cambiar. La empresa estableció una serie de restricciones para arrieros, pirquineros, vecinos y visitantes que deseaban acceder a la montaña, donde existen cursos de agua que deberían ser de libre acceso, así como rutas históricas vinculadas con las guerras de emancipación americana (por ese lugar la columna encabezada por el general José de San Martín cruzó la cordillera de Los Andes durante la campaña libertadora en 1817). Para materializar el control monopólico del territorio se instaló un portón en el acceso principal al predio.

Estas acciones coincidieron, no casualmente, con el cambio en las fuentes de ingreso de la empresa. Hasta el momento la misma obtenía cobros constantes pero pequeños por el talaje (a modo de ejemplo, en diciembre de 2019 el monto pagado por todos los talajeros ascendía a alrededor de 25.000 .000 de pesos chilenos anuales, unos 30.000 dólares de diciembre de 2017), que se sumaban a los reembolsos de compañías mineras, que tenían intenciones de extraer material de la zona (Entrevistas P06 y P07). Sin embargo, a inicios de la década de los 2000 comenzó a registrarse una serie creciente de retribuciones que el Estado realizó a la Ganadera Tongoy en concepto de servidumbre o expropiaciones por obras de infraestructura. Como puede observarse en la Tabla 1, entre 2002 y 2003 la empresa -junto a otros particulares, pues algunas de esas expropiaciones incluían porciones de tierras de vecinos- recibió casi 180.000 dólares en dicho concepto, el equivalente a casi 6 años de derechos de talaje. A partir de 2010 se iniciaron las acciones estatales para la construcción del embalse Chacrillas, cuyo objetivo fue mejorar la disponibilidad de agua para el sistema de riego del valle. Para concretar esta obra de infraestructura se expropiaron exclusivamente a Tongoy 169,61 ha por un precio de 1.476.663,46 de dólares de diciembre de 2017, equivalente a 49 años de ingresos por el pago de talaje. 
Tabla 1. Área expropiada y montos pagados por el Estado a la Ganadera Tongoy

\begin{tabular}{|l|r|r|r|r|}
\hline \multicolumn{1}{|c|}{ Fecha } & \multicolumn{1}{c|}{$\begin{array}{c}\text { Hectáreas } \\
\text { expropiadas }\end{array}$} & $\begin{array}{c}\text { Pesos } \\
\text { corrientes }\end{array}$ & \multicolumn{1}{c|}{$\begin{array}{c}\text { Dólares } \\
\text { corrientes }\end{array}$} & $\begin{array}{c}\text { Dólares constantes } \\
\text { (diciembre de 2017) }\end{array}$ \\
\hline $29 / 10 / 2002$ & 0,3 & 931.500 & $1.278,3$ & $1.779,4$ \\
\hline $10 / 3 / 2003$ & 11,99 & 48.484 .500 & 64.066 & $85.742,7$ \\
\hline $30 / 7 / 2003$ & 1,81 & 8.279 .050 & $11.789,8$ & $15.804,6$ \\
\hline $31 / 7 / 2003$ & 2,15 & 8.787 .750 & $12.453,6$ & $16.694,4$ \\
\hline $25 / 7 / 2003$ & 3,93 & 26.176 .700 & $37.201,8$ & $49.870,3$ \\
\hline $31 / 7 / 2003$ & 0,83 & 3.780 .700 & $5.357,8$ & $7.182,3$ \\
\hline $22 / 8 / 2003$ & 0,15 & 446.400 & 669,9 & 891,7 \\
\hline $30 / 3 / 2010$ & 107,12 & 275.237 .800 & $517.160,1$ & 585.819 \\
\hline $30 / 3 / 2010$ & 53,44 & 366.589 .799 & $688.806,7$ & 71.924 \\
\hline $10 / 4 / 2012$ & 7,25 & 32.630 .850 & $67.127,8$ & $20.412,6$ \\
\hline $22 / 9 / 2015$ & 0,9 & 13.450 .110 & $19.702,2$ & $18.254,3$ \\
\hline $9 / 12 / 2017$ & 0,9 & 11.935 .000 & $18.254,3$ & 1.654 .629 \\
\hline Total & 190,77 & 796.730 .159 & $1.443 .868,4$ & \\
\hline
\end{tabular}

Fuente: Elaboración propia a partir de decretos Ministerio de Obras Públicas de Chile y deflactado con datos del Sistema de Impuestos Internos y del Bureau of Labor Statistics.

La venta o concesión de terrenos para infraestructura y locaciones (ya sea al Estado o el proyecto Vizcachitas, que, como veremos en el próximo apartado, se emplaza en sus tierras) se convirtió en el negocio más atractivo para Tongoy. Al ser la principal motivación de una empresa capitalista maximizar las ganancias, resulta lógico y necesario un cambio en la estrategia de territorialización: un territorio "vacío" -sin ganados ni ganaderos- es más fácil de adjudicar a otras actividades más rentables.

Esta situación supuso el viraje desde una estrategia de control de las formas de uso y de acceso a los territorios hacia una desterritorialización efectiva de algunas familias campesinas. Si bien en nuestra última visita a terreno a finales de 2019 aún había alrededor de 50 ganaderos que tenían animales (unos 2000 vacunos y 900 caprinos) (Entrevistas P06 y P07), desde 2015 comenzaron las disputas judiciales para el desalojo de familias criadoras de cabras del sector de El Manzano y Las Minillas. En ese marco, la Comunidad de Crianceros de El Manzano desarrolló una estrategia que combinaba la permanencia en las tierras serranas, con el impulso de procesos institucionales que debían probar la adquisición irregular por parte de la empresa de las tierras comunes de la Reforma Agraria. A mediados de 2016, unas 30 familias del sector iniciaron una toma/recuperación de las serranías. La misma supuso el fortalecimiento de los lugares de asentamiento y la suspensión del pago de los arrendamientos. Según los campesinos:

La toma [forma en que la comunidad llamó esta acción colectiva] es la continuación del proceso de resistencia a la humillación, prepotencia y despojo practicado por una fantasmagórica Ganadera Tongoy [... y] la recuperación definitiva de nosotros mismos como crianceros orgullosos de esta vida, como comunidad digna y capaz (Comunidad de Crianceros El Manzano, 31 de agosto de 2016).

A partir de la memoria de las acciones políticas de mediados del siglo XX, estos campesinos reactualizan la conflictividad constitutiva de la cuestión agraria: el acceso a la tierra. En la cita se condensa la territorialidad de la comunidad y se evidencia que la disputa no se acota al control de un espacio geográfico, sino que supone la afirmación del "colectivo criancero" como digno y capaz. La "recuperación territorial" es también una recuperación identitaria. Los adjetivos conllevan una doble operación de reconocimiento: por un lado, con la dignidad se reclama el respeto a un modo de habitar el espacio diferente del hegemónico; por el otro, con la capacidad se reivindica un saber hacer idóneo para afrontar la reproducción cotidiana de la vida. La nueva "toma del fundo" se asienta en un sentido de pertenencia hacia el lugar habitado, respecto del cual ya habían 
pagado muchos años de arriendo, y además habían dejado huellas en sus terrenos y cuerpos. A partir de esa memoria de lucha plantearon: "en nuestro cerro, sin pedirle permiso a nadie comenzamos a ejercer nuestra soberanía” (Comunidad de Crianceros El Manzano, 31 agosto de 2016).

La acción directa de la toma supone un posicionamiento en torno al espacio (territorialidad) que colisiona con el de la Ganadera Tongoy, la cual responde desplegando mecanismos judiciales tendientes al desalojo. En ese marco, en julio de 2019 la Corte Suprema de Justicia de Chile ordenó la restitución de los terrenos, en los que se encontraban asentadas dos familias campesinas (Corte Suprema de Justicia, 04 de julio de 2019a y 04 de julio de 2019b). La argumentación del tribunal fue que los contratos de talaje celebrados por la empresa y los crianceros no incluían la construcción de viviendas e instalaciones. Así, a pesar de reconocer que las casas tenían entre 15 y 30 años, se dictó el desalojo sin tomar en cuenta las formas específicas de la vida criancera. De hecho, la cría de caprinos para la producción de quesos requiere de la presencia permanente de personas con el rebaño tanto para su cuidado como para el ordeñe y procesamiento de los lácteos. Al afectar a las familias que carecían de tierras en la zona de regadío, este fallo implicó la pérdida total de un territorio donde desarrollar sus actividades. Algunos entrevistados (P01 y P14) señalaron que este accionar de la empresa en relación a los crianceros, que históricamente vivieron -y pagaron- por el uso de la tierra, se debe a la connivencia entre la ganadera y la empresa minera Andes Copper. A partir de estos desalojos se buscaría crear una zona liberada de modos de vida que pudieran afectar la instalación de infraestructura para el proyecto extractivo.

Como veremos con más detalle en los próximos apartados, esta situación ha transcurrido en el marco de una sequía muy fuerte, que llevó a declarar en agosto de 2019 la "emergencia agrícola” en toda la región de Valparaíso, y semanas después la “zona de catástrofe”. En ese contexto la empresa se negó a dar paso a algunos crianceros por sus tierras para que pudieran llevar anticipadamente los animales a los pastos de altura, como estrategia para evitar la muerte de los mismos por sed o inanición. Los impactos de la escasez de precipitaciones fueron más intensos en aquellas familias que solo disponían de tierras de secano, ya sea por haber llegado a la zona después de la Reforma Agraria, por haber vendido, o por haber perdido por endeudamiento las parcelas con riego. De hecho, aun cuando la escasez hídrica era general en la comuna, los crianceros que contaban con tierras irrigadas donde cultivar forraje o pastorear el barbecho estaban en una situación menos frágil (Entrevistas P02, P04, P07, P09, P17, P18 y P22).

Junto a los desalojos, también se han registrado otras tensiones entre la empresa y los criadores que llevan ganado mayor (vacunos, equinos y mulares) a pastar a la cordillera. En 2018 los 61 ganaderos que utilizaban las tierras de la Ganadera Tongoy crearon la Agrupación de Pequeños Ganaderos de El Chalaco, Putaendo, con el fin de negociar colectivamente los arriendos y condiciones de tránsito en las serranías. Si bien esto no tuvo efectos positivos en la relación con la Ganadera, sí permitió obtener ayudas estatales para enfrentar condiciones climáticas adversas (forrajes, vacunas, etc.) y problematizar el proceso a partir del cual los antiguos parceleros perdieron la tierra de secano. Como expresa uno de ellos:

si hubiéramos estado nosotros en ese tiempo no nos quitan el cerro, pero la mayoría eran analfabetos, no sabían leer, todos mis tíos que tenían parcela no sabían leer, mi papá no sabe leer y el caballero de aquí más arriba tampoco. Entonces con cualquier cosa lo asustaron y le quitaron. Dicen que hay una posibilidad de recuperarla pero pasa que los parceleros murieron muchos y otros vendieron, y no hay plata para pagar a un abogado para que haga una defensa (Entrevista P07).

La persistencia de la sensación de injusticia del hecho a partir del cual los parceleros perdieron la propiedad de las tierras comunes reaparece como un elemento de tensión. Frente a ello los ganaderos buscaron convertir esta situación en un "asunto socialmente problematizado" (Oszlak y O'Donnell, 1995), es decir, en una cuestión que amerite el posicionamiento y la acción de fracciones de clase, organizaciones, grupos o individuos. La estrategia desplegada se ha basado en las denuncias en medios de comunicación, la recuperación de documentos y testimonios sobre el acontecimiento, y una búsqueda vía judicial que permitiera recuperar las tierras. Como plantea la cita, este último camino suponía contar con una cantidad de dinero que estaba fuera del alcance de los ganaderos. 
En síntesis, la investigación permitió observar los procesos de territorialización, desterritorialización y reterritorialización de las tierras cordilleranas, y cómo ellos configuran distintas intensidades, momentos y lugares del conflicto territorial. En ese contexto emergen al menos dos elementos que merecen señalarse. Por un lado, los crianceros caprinos de la zona de El Manzano y Las Minillas han activado una estrategia de resistencia a partir de los intentos de desalojo. La mayor precariedad de su situación -producto de la falta de títulos, pero también de tierras de regadío- queda en evidencia en las sentencias judiciales que dictan su desalojo. Por el otro lado, los criadores de ganado mayor, quienes tras la llegada de Tongoy parecieron aceptar su territorialización a partir del pago de los derechos de talaje, han mantenido en la memoria el sentido de injusticia que marcó el arribo de la empresa. Su organización es reciente pero ha permitido reunir a los herederos de los viejos parceleros y problematizar el origen de la desigualdad a partir de acciones incipientes. En ambas disputas se registran destellos de una "ambientalización” de la lucha (Leff, 2004), principalmente en relación a un proyecto de gran minería en las tierras de Tongoy, que en cierto sentido también son sus tierras. A partir de la conflictividad socioambiental, que desarrollaremos en las próximas páginas, veremos los puntos de contacto entre ambos procesos.

\section{EL CONFLICTO EN TORNO A LA GRAN MINERÍA}

Si bien existen diversas zonas concesionadas para la explotación minera en la comuna de Putaendo, y una rica tradición de pequeña y mediana minería, la escala y los mecanismos de intervención en el territorio del proyecto Vizcachitas han despertado importantes resistencias. Los primeros sondajes en el sector de Las Tejas se hicieron hace alrededor de 30 años (Entrevistas P14, P23 y P24), pero fue en 2007 cuando el tema comenzó a resonar en la población de la comuna. Ese año, la empresa canadiense Los Andes Copper adquirió los derechos del prospecto minero con el objetivo de instalar una mina a cielo abierto para la extracción de cobre y molibdeno. Una de sus primeras acciones fue presentar en 2008 una Declaración de Impacto Ambiental, a fin de ser evaluada por el Servicio Evaluación Ambiental (SEA). La misma contemplaba la realización de unos 200 sondajes en un área de 290 ha en el plazo de 5 años, a fin de confirmar la factibilidad económica del proyecto. Las autoridades rechazaron la propuesta por observaciones a: el plan de contingencias y preemergencias; las medidas de cuidado de la fauna y flora local; el tratamiento de aguas servidas; la restitución del suelo agrícola; la seguridad vial; la alteración de sitios patrimoniales; entre otras (SEA, 21 de octubre de 2008).

Esta prohibición no impidió que la empresa realizara varias faenas de menor envergadura, y, según denuncian las propias organizaciones (Entrevistas P01, P05, P24 y P25), concretó numerosos sondajes valiéndose de ciertos vacíos legales. Parte importante de las operaciones mineras se emplazan en el mismo lecho del río Rocín, afluente del Putaendo, y a escasos kilómetros de glaciares de roca, ambos representan aportes significativos de agua a los ríos del valle. Si bien el proceso extractivo como tal no ha comenzado, los trabajos realizados generaron una movilización de pobladores de la comuna, quienes denuncian que ya se registran impactos importantes:

en la cuenca misma del río Rocín está la zona mineralizada y ellos para descubrir eso y tener la certeza de que eso está ahí hicieron sondajes de hasta 1000 metros de profundidad, rotulados por ellos (...) Al perforar alrededor de 300 sondajes en el lecho del río hicieron prácticamente un resumidero y estos sondajes son de alrededor de los 40 milímetros aproximadamente, más y menos, y partamos de 300 a 1000 metros o 1500. Si tenemos sondajes de 1000 metros de profundidad en la cota donde está Las Tejas, el agua pasa por debajo de Putaendo (Entrevista P25).

A este diagnóstico local en torno a los efectos de las labores mineras en la cantidad de agua disponible se suman dos elementos más, que los entrevistados (P01, P02, P05, P18, P24 y P25) mencionan reiteradamente. Por un lado, la afectación de la calidad del agua (por elevadas concentraciones de aluminio, cobre, manganeso 
y hierro) a raíz de las faenas ya realizadas. Por el otro, los impactos del proyecto sobre el embalse Chacrillas, específicamente la reducción de su vida útil por el arrastre del material removido.

La problematización acerca de las consecuencias socioambientales, actuales o potenciales, del proyecto de gran minería comenzó a gestarse paulatinamente entre finales de 2014 y 2015. En esos momentos, un grupo de vecinos (principalmente agricultores, pequeños mineros, arrieros, profesionales y comerciantes que luego crearían la Coordinadora Tres Ríos) organizó una serie de reuniones, a las que llamaron asambleas informativas, tanto en la ciudad cabecera de la comuna como en las localidades rurales. Este proceso de intercambio y construcción de información acerca de la gran minería en general, y el proyecto Vizcachitas en particular, fue creciendo e involucrando a nuevos actores. En ese contexto otro grupo, mayoritariamente de jóvenes profesionales, creó el Movimiento Socioambiental Putraintú, y algunos años después el espacio de articulación general de las organizaciones que se oponían a la gran minería (llamado Putaendo Resiste) adquirió también el estatus de organización. Estos tres colectivos de conformación social y etaria heterogénea se han focalizado en la oposición a la gran minería materializada tanto en el proyecto Vizcachitas como en otros más incipientes, como el proyecto Fénix, antiguamente denominado Amos-Andrés, ubicado sobre la frontera entre Argentina y Chile. Las acciones motorizadas por estas organizaciones convirtieron al proyecto Vizcachitas en un asunto sobre el que amplios sectores de la comuna debieron sentar posición.

Como se mencionó anteriormente, el significante que ha funcionado como principal referencia en las acciones de protesta y discursos de las organizaciones socioambientales ha sido la centralidad del agua como elemento articulador de la vida de la comuna de Putaendo. Este punto queda en evidencia en el testimonio de uno de los miembros de la agrupación Putaendo Resiste:

este valle es nada sin agua, si no hay agua estamos fritos, y este proyecto se ubica en el lecho del río, del principal afluente del río Putaendo, que aunque lo vemos seco el río está, está canalizado, corre por canales de riego (...) Y sabemos que si ese caudal se hipoteca, se pone en riesgo de vida, todo lo que está regando desaparece, y si eso desaparece, desaparecen formas de vida, se termina cultura, se terminan miles de empleos, entonces por eso es que es tan fundamental (Entrevista P24).

El cuidado de lo común, que según nuestra perspectiva definiría la contienda socioambiental, tiene su expresión en el agua y sus fuentes de generación (glaciares de roca, humedales, escurrimientos). Esta referencia aparece en casi todos los testimonios recabados, tanto de aquellos actores directamente involucrados a las organizaciones como de agricultores, ganaderos o funcionarios. Existe cierto consenso acerca de la importancia vital que tiene la disponibilidad cuantitativa y cualitativa de agua en el río Putaendo. Las prácticas agrícolas y ganaderas, pero también el acceso a los servicios sanitarios básicos de la población, son articuladas justamente por la disponibilidad del recurso hídrico. Este sentido se ha reforzado particularmente en los últimos años a causa de la sequía periódica. Entre 2008 y 2019 la comuna de Putaendo fue declarada por el estado nacional como "zona de escasez hídrica" 12 veces, y ha pasado un total de 69 meses en dicha condición (DGA, 01 de febrero de 2018).

Las organizaciones han recurrido a un amplio repertorio de acciones colectivas (Tilly, 1978), tanto directas como institucionales, a fin de interpelar a otros actores de la comuna. En primer lugar, se desplegó un proceso de construcción de un saber contraexperto (Svampa, 2019) a partir del diálogo entre el conocimiento académico-científico y los saberes locales. Para su difusión combinaron las mencionadas asambleas informativas -orientadas principalmente a adultos y mayores- con la creación de contenidos digitales para las redes sociales (Whatsapp, Facebook, Instagram, entre otras), que suelen enfocarse en el público más joven. Como se observa en la Figura 2, este tipo de recursos se centran en frases concisas y un fuerte acompañamiento de imágenes e iconografía. En el ejemplo reproducido se presenta un contexto general signado por las bajas precipitaciones y la reducción del caudal de los ríos de la región, y este mensaje es reforzado por la imagen de fondo de la tierra agrietada por la falta de agua. El nudo del mensaje construye un escenario de incompatibilidad entre la minería y las actividades típicas del valle, a partir del cual interpela directamente al lector al inquirirle: “y tú qué vas a hacer?”. En esta pregunta hay una huella clara de la conformación de la problemática como algo común a toda la población de la comuna. Frente a ello la 
interrogación se dirige, en términos generales, a quienes aún no han tomado posición contra la minería, y en un registro más particular a quienes aún no han llevado adelante ningún curso de acción que enfrente este asunto, del cual no se puede salir indemne.

Figura 2. Infografía difundida por el Movimiento Socioambiental Putraintú
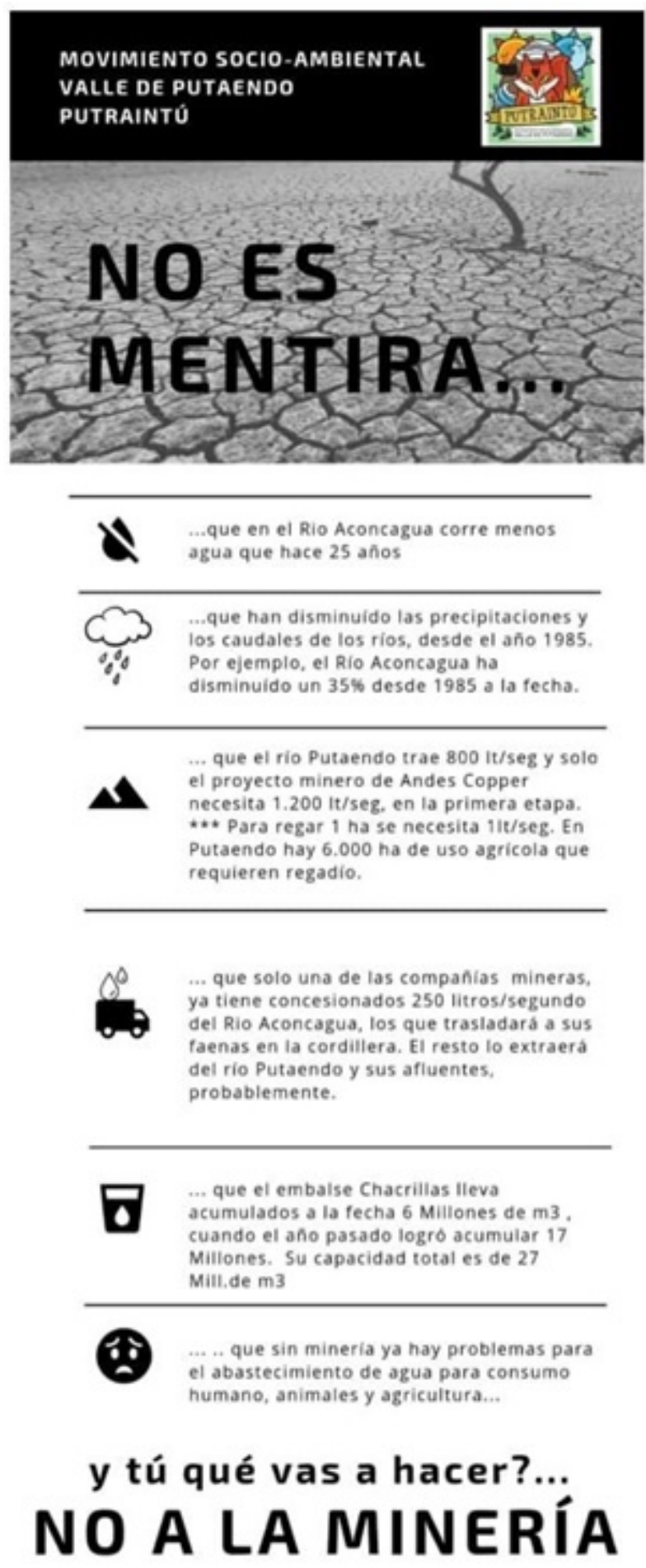

Tal y como afirma Sobreiro Filho (2017), recuperando los aportes de Tarrow y de Lietner, las acciones contenciosas -como acciones políticas y sociales que desafían el sistema hegemónico y buscan establecer 
proyectos y valores alternativos- tienen una profunda articulación con el espacio. Las mismas, en tanto interpelan al Estado como actor hegemónico por excelencia, operan en las múltiples escalas del primer territorio (Fernandes, 2008), pero también avanzan en articulaciones que pueden crear nuevos espacios e instancias de gobernanza que evite el monopolio de la decisión en las diversas esferas gubernamentales. En este marco, las principales estrategias de visibilización a nivel local han sido las reuniones a lo largo de la comuna -cuya mayoría poblacional se asienta en pequeños poblados-, la participación en medios de comunicación locales, marchas, cortes de ruta y manifestaciones artísticas (conciertos, murales, etc.). Las movilizaciones y encuentros más grandes y numerosos han trascendido las fronteras comunales e incluido a actores provinciales y regionales. Finalmente, en momentos de alta movilización, las organizaciones han realizado acciones a escala nacional a través de la interpelación a parlamentarios en pos lograr algún tipo de normativa que fortalezca su resistencia, y manifestaciones y presentaciones a instituciones estatales en Santiago o Valparaíso (Entrevistas P01, P03, P05, P24 y P25). Como plantea Diani (1998), estas acciones operan en un doble registro. Por un lado, refuerzan la identidad colectiva de las organizaciones a la vez que permiten la incorporación de nuevos miembros. Por el otro, crean vínculos de cooperación e intercambio con otros actores que, sin pasar a formar parte orgánica de los colectivos, adhieren a las demandas de forma coyuntural.

Como ejemplo de este tipo de estrategias, y las encrucijadas que representa en la conflictividad socioambiental, el 31 de mayo de 2019 los responsables del proyecto Vizcachitas, con el aval del Consejo Regional, ingresaron al SEA de Valparaíso una nueva Declaración de Impacto Ambiental para la ejecución de hasta 350 nuevos sondajes. En respuesta, las organizaciones de la comuna recolectaron alrededor de 2000 firmas de personas físicas y jurídicas para solicitar a los organismos públicos la apertura y garantía de un proceso de participación ciudadana. Varios meses después, el SEA (17 de marzo de 2020) emitió una resolución en donde rechazaba el pedido de los vecinos. Los argumentos de la citada resolución se centraron en el hecho de que la legislación vigente considera válida la participación ciudadana solo en el caso de proyectos que generan tanto beneficios sociales como externalidades ambientales negativas. En tanto la definición de beneficios sociales se acota a una utilidad directa en la "mejora del nivel de bienestar social o condiciones de vida de las comunidades próximas" (SEA, 17 de marzo de 2020, $\$ 17$ ) que el proyecto de sondaje no provee, el SEA decidió rechazar la participación ciudadana. Este caso puede considerarse como un ejemplo de las tensiones en torno a cómo define la legislación aquello que representa una preocupación común, que justifique la intervención directa de las personas potencialmente afectadas. Al restringir la participación ciudadana a aquellas situaciones en donde los beneficios son comunes (por ejemplo líneas o centrales eléctricas o sistemas de agua potable o alcantarillado público), quedan fuera de consideración las declaraciones de proyectos que, aun cuando prevén externalidades ambientales negativas, no suponen la mejora directa de la calidad de vida de las comunidades. Huelga decir que dentro de esta categoría podría incluirse el amplio abanico de actividades económicas vinculadas al modelo extractivo.

A pesar de este tipo de paradojas, la dimensión institucional ha tenido un fuerte peso en el repertorio de acciones de las organizaciones. En primer lugar, muchas de ellas han tramitado la personería jurídica a fin de poder participar formalmente en las numerosas reuniones en dependencias estatales. En segundo término, una de las acciones que los entrevistados destacan en términos de trascendencia fue el emplazamiento a las autoridades comunales que realizaron en 2015. Esto consistió básicamente en el pedido formal a los gobernantes locales para que tomen posición pública en relación al proyecto de gran minería. Frente a esta solicitud, y en el marco de un ascenso del ciclo de movilizaciones, el municipio de Putaendo adquirió una posición contraria al proyecto Vizcachitas argumentando la incompatibilidad entre el modo de vida local y las transformaciones socioeconómicas implícitas en la instalación de la gran minería. Puntualmente esto se tradujo en el apoyo oficial a actividades contra el proyecto, la participación de los funcionarios en las movilizaciones y la realización, junto a científicos de diversas universidades, de expediciones a la zona alta de la comuna con el fin de registrar glaciares de roca y humedales altoandinos. Además, el municipio reforzó su 
rol en las instancias de evaluación del proyecto a través de la solicitud de estudios adicionales para determinar el impacto de las nuevas etapas o la sanción a la empresa por construir el campamento sin permisos de edificación, obligándola a desmantelarlo (Entrevistas P14, P23 y P24).

Un proceso de interpelación similar ocurrió con la Junta de Vigilancia del Río Putaendo. Esta institución nuclea a todos los regantes del valle pero, por la legislación vigente (Junta de Gobierno de la República, 13 de Agosto de 1981), suele tener una participación preponderante de los actores locales con mayor cantidad de acciones de agua -y por tanto de tierra de cultivo-. A poco de iniciado el conflicto esta institución adoptó una posición contraria a la gran minería, con el argumento de que la escasez del agua la torna incompatible con la agricultura. De hecho, la Junta decidió contratar un equipo de abogados que actúa permanentemente en instancias judiciales y administrativas denunciando irregularidades en el proyecto minero. A finales de 2019, la DGA multó por 60 millones de pesos a la empresa minera por usurpación de aguas y desvío de caudal a raíz de una denuncia de la Junta (Entrevistas P13, P14 y P22).

\section{LA INTERFAZ DE LOS CONFLICTOS}

Los aportes teóricos recuperados al inicio de este texto advierten la creciente superposición entre las demandas ambientales y las territoriales. Si bien en la comuna de Putaendo pueden distinguirse claramente dos conflictos - uno en torno a la propiedad o control de las formas de uso y de acceso de las pasturas de altura, y el otro en torno al proyecto de gran minería-, también emergen de las acciones y testimonios algunos puntos de encuentro. En este sentido, más que pensar en una división tajante, proponemos caracterizar las disputas a partir de un continuum en el cual se distribuyen los elementos territoriales (vinculados al control efectivo del uso y acceso a un espacio determinado) y los socioambientales (que involucran el sostenimiento de un espacio común comprendido bajo la denominación genérica de ambiente o naturaleza).

En nuestro caso, el denominador común se encuentra en la articulación entre las dos empresas que conforman los polos antagónicos de cada una de las disputas: la Ganadera Tongoy y la minera Vizcachitas Holding. A medida que el conflicto territorial se fue desarrollando, las comunidades y organizaciones campesinas articularon en su discurso la denuncia al accionar conjunto de las empresas. De hecho, para los crianceros entrevistados el recrudecimiento de las restricciones al paso y los desalojos encuentran su explicación en la gran asimetría de las fuentes de ingresos de la Ganadera:

entre todos los crianceros la temporada serán unos 20 o 30 millones que le generan a la empresa y si se instala este proyecto minero no van a ser 30 millones, va a ser mucho más. Porque son empresas tan grandes que no les interesa recibir un par de millones en concepto de arriendo de talaje (Entrevista P02).

De allí que algunos comunicados de la Comunidad de Crianceros El Manzano, como el citado anteriormente, expresen directamente que sus acciones son "la única base real y posible de devolverle a estos montes la vida, el verdor y la frescura arrebatada; es también, adelantarnos a intereses voraces, ávidos de sus entrañas fecundas" (31 de agosto de 2016). A partir de ese diagnóstico se comprende el final del comunicado (“iiLA MINERA NO, LA TONGOY TAMPOCO!!”), que supone también el acercamiento de las luchas. En este sentido, la configuración particular que adquirió la conflictividad reciente en Putaendo está marcada por la articulación entre las empresas. Es difícil afirmar el grado de coordinación entre Andes Copper y Tongoy, pero la motivación última de la empresa capitalista (la maximización de las ganancias) funciona como un mecanismo estructural de cooperación. En su escenario ideal, la instalación del proyecto de gran minería les significaría a ambas compañías importantes dividendos. Es, en suma, una conflictualidad producida por la expansión de proyectos de desarrollo capitalista asentados en la exportación de productos primarios.

Por su parte, existe un consenso entre los entrevistados de las organizaciones socioambientales acerca de la dificultad adicional que representa la presencia de la Ganadera Tongoy en relación a la posibilidad de detener 
el proyecto de Vizcachitas Holding. En este punto el carácter transnacional de la empresa agropecuaria y la ausencia de una representación duradera en el territorio comunal (algo que contrasta tanto con el pasado hacendal como con la actual forma de aprovechamiento colectivo de las tierras de las 5 comunidades identificadas en la Figura 1) refuerzan el carácter foráneo de la misma. El hecho de que ese espacio "no sea de Putaendo" se configura como un argumento central a la hora en que los actores analizan la facilidad con que la minera ha realizado sus faenas en los años recientes:

...lamentablemente, el sector de la cordillera donde nace el agua de los putaendinos no es de los putaendinos, es de privados. El dueño de toda esa cordillera es una empresa que se llama Ganadera Tongoy... Entonces claro, si nosotros fuéramos dueños de la cordillera sería otro el cuento, sería otra la lucha (Entrevista P05).

...nosotros aquí en Putaendo con la instalación de las empresas y esta minera nosotros perdimos soberanía. Putaendo llega hasta una puerta, que está en el Resguardo Los Patos, inmediatamente hay una puerta que es de la Ganadera Tongoy que es una empresa privada donde no te dejan pasar. Hasta ahí llega Putaendo, antes llegábamos a la Argentina, hoy llegamos a la Ganadera Tongoy. Y después, si logramos pasar la Ganadera Tongoy, está la minera y eso es una violación a un derecho humano, un derecho a la soberanía (Entrevista P25).

En ese sentido, el despojo territorial a los campesinos prefigura un escenario que facilita la instalación del proyecto extractivo y ancla la disputa en una escala -lo transnacional- a la que los actores locales no pueden acceder, o lo hacen de manera muy parcial. Además, ello contrasta fuertemente con el hecho de que la Comunidad La Victoria de Piguchén -que nuclea a los parceleros del asentamiento homónimo que mantuvieron la propiedad común de los campos cordilleranos con su territorialización específica (punto 5 de la Figura 1) - ha mostrado una postura antagónica. A partir del proyecto de conformación de un Santuario de la Naturaleza en el sector de Las Launas, se busca resguardar los humedales altoandinos que se encuentran en sus tierras y forman parte de la cuenca superior del río Hidalgo, uno de los afluentes del río Putaendo (Entrevistas P02, P05, P09, P14 y P23).

En paralelo, la centralidad que tiene "el agua" en la disputa socioambiental ha permitido la construcción de un amplio consenso acerca de los peligros del proyecto de gran minería en la reproducción de la vida cotidiana del valle. Sin embargo, allí también se registran tensiones entre actores de diversas escalas, especialmente los empresarios locales capitalizados y los pequeños agricultores. Mientras los primeros han logrado incorporar tecnología y contar con "derechos de aprovechamiento de agua" suficientes para llevar adelante sus explotaciones, los segundos se encuentran en una situación cada vez más precaria, a raíz de la implementación de turnos de riego y venta de horas de agua en momentos períodos de sequía (Entrevistas 2, 7, 16, 18, 19 y 20). Así, aquel significante que opera como aglutinador de la lucha socioambiental puede implicar también un disparador de tensiones propias de las estructuras agrarias en proceso de concentración.

\section{REFLEXiONES FINALES}

En este trabajo hemos analizado distintos matices de la conflictividad en territorios rurales marcados por la expansión del modelo extractivo. En ese sentido, la comuna de Putaendo supone un escenario privilegiado donde se registran tanto conflictos territoriales como socioambientales, los cuales, lejos de presentarse en formas puras, muestran un interesante solapamiento. A medida que la frontera extractiva avance será más probable encontrar este tipo de situaciones, en las que dinámicas especulativas tradicionales se articulan con nuevas actividades primario exportadoras. La propuesta teórico-analítica de sostener la diferenciación entre ambos tipos de disputas, a pesar de su frecuente superposición, se ancla justamente en la necesidad de ahondar en la especificidad que se despliega en cada territorio. Ello no implica desconocer los puntos comunes, sino analizarlos a la luz de las historias y memorias en las que cada conflicto se basa. A partir de múltiples técnicas de investigación es posible reconstruir diversos elementos que caracterizan los conflictos y sus interfaces. Para ello es importante priorizar la posición de los actores involucrados, y tomarlas como punto de partida para cualquier interpretación posible de sus acciones. 
En términos específicos, ese abordaje permitió identificar algunas líneas explicativas relevantes tanto para pensar el caso como para abonar al corpus de estudios de los conflictos sociales en el marco del modelo extractivo. Por un lado, la comprensión de la disputa en torno a los campos de cordillera supone la consideración de dinámicas de territorialización-desterritorialización-reterritorialización ocurridas a lo largo de las últimas décadas. Las marcas que dejó en el espacio, y en las memorias, tanto la Reforma Agraria como la Contrarreforma suponen elementos nodales para comprender las diversas etapas de la conflictividad territorial. El control de ese espacio se juega en la legitimidad -o injusticia- de la posesión, pero también en la forma en que los actores logran politizar esa tensión. Asimismo, los procesos más recientes -que incluyen desalojos pero también incipientes articulaciones de los campesinos- están conectados a la avanzada minera en las tierras cordilleranas. Esto supone la posibilidad o materialización de un importante acercamiento entre los actores. Por otro lado, la conflictividad socioambiental abreva de procesos más recientes. La búsqueda de nuevos yacimientos de explotación metalífera puso a la comuna de Putaendo dentro del mapa de la gran minería. Así se revitalizaron proyectos que ya tenían algunas décadas, esta vez motorizados por la dinámica transnacional. La tradición minera de Chile no funcionó, prima facie, como garantía para el desarrollo del proyecto Vizcachitas. Por el contrario, ante las primeras faenas, un heterogéneo grupo de actores sociales se fue articulando en oposición a la gran minería, a partir de subrayar la importancia del agua para la reproducción de la vida del valle. En cierto sentido, estas acciones suponen una expansión de los espacios de gobernanza territorial más allá de los típicamente estatales, pues amplían la cantidad y diversidad de grupos sociales involucrados en decidir cuál es el modelo de desarrollo deseable para la comuna.

La reconstrucción analítica de estas dos conflictividades permitió también relevar sus puntos de interfaz. Varios de los campesinos entrevistados vinculan el último ciclo de conflictividad en torno a las tierras cordilleranas con la aparición del proyecto minero. El cierre definitivo de ese espacio, simbolizado en la instalación del portón, supuso una nueva territorialización de la Ganadera Tongoy, pero también el inició de su articulación con Vizcachitas Holding. Allí está uno de los elementos que refuerza la oposición de los crianceros al proyecto minero, y se suma a la querella en torno al agua disponible. Simultáneamente, los miembros de las organizaciones socioambientales ubican a la disputa territorial por las pasturas cordilleranas como un punto nodal en su propia lucha: si esa tierra fuera de los putaendinos, "sería otro el cuento" (Entrevista P05). Este cruce pone luz en las formas en que la conflictualidad se expresa.

Finalmente, el abordaje del caso de Putaendo posee una riqueza que no puede agotarse en este trabajo. Quedan para próximas reflexiones puntos importantes como aquellas tensiones que se vislumbran en torno a la gestión del agua de riego o la contraposición específica que puede desarrollarse entre los productores de mayor escala y el proyecto minero, en caso que el mismo logre avanzar.

\section{Agradecimientos}

En primer lugar, quiero expresar mi gratitud a las personas de Putaendo por sus testimonios y hospitalidad. En segundo lugar, agradezco los comentarios que me realizaron a una versión previa de este trabajo en el IX Simpósio Internacional de Geografia Agrária (Recife 2019), la lectura atenta de Julieta Godfrid, Paolo Giotti y Gustavo González, y las recomendaciones del Equipo Editorial de Mundo Agrario y los evaluadores anónimos. La investigación fue financiada con el proyecto FONDECYT Posdoctorado $\mathrm{N}^{\circ} 3190153$ "Transformaciones en territorios rurales a partir de la expansión de actividades primario exportadoras. Los casos de la Comuna de Putaendo (Valparaíso, Chile) y el Valle este del Famatina (La Rioja, Argentina)".

\section{REFerenCias Bibliográficas}

Alimonda, H., Toro Pérez, C., y Martín, F. (coord.) (2017). Ecología política latinoamericana: pensamiento crítico, diferencia latinoamericana y rearticulación epistémica. México: Universidad Autónoma Metropolitana. 
Baraona, R., Aranda, X., y Santana, R. (1961). Valle de Putaendo. Estudio de estructura agraria. Santiago de Chile: Instituto de Geografía, Universidad de Chile.

Bengoa, J. (2015). Historia rural de Chile Central. Tomo I. Santiago de Chile: LOM ediciones.

Bolados, P. (2016). Conflictos socio-ambientales/territoriales y el surgimiento de identidades post neoliberales (Valparaíso-Chile). Izquierdas, 31, 102-129.

De Matheus e Silva, L. F. (2016). Desposeer para acumular: reflexiones sobre las contradicciones del proceso de modernización neoliberal de la agricultura chilena. Mundo Agrario, 17(34), e007.Recuperado de http://www. mundoagrario.unlp.edu.ar/article/view/MAv17n34a07/7220

Diani, M. (1998). Las redes de los movimientos: una perspectiva de análisis. En P. Ibarra y B. Tejerina (ed.), Los movimientos sociales. Transformaciones politicas y cambio cultural (pp. 243-270). Madrid: Trotta.

Fernandes, B. M. (2005). Movimentos socioterritoriais e movimentos socioespaciais: contribuição teórica para uma leitura geográfica dos movimentos sociais. Revista NERA, 8(6), 24-34.

Fernandes, B. M. (2008). Entrando nos territórios do Território. En E. T. Paulino y J. E. Fabrini (ed.), Campesinato e territórios em disputas (pp. 273-302). São Paulo: Expressão Popular.

García Gatica, T., y Thayer Escalona, C. (1970). Reforma agraria y pequeña propiedad: estudio del área AconcaguaPutaendo. Investigaciones Geográficas, 20, 103-139.

Giarracca, N., y Teubal M. (2013). Las actividades extractivas en Argentina. En N. Giarracca y M. Teubal (coord.), Actividades extractivas en expansión ¿Reprimarización de la economía argentina (pp. 19-43). Buenos Aires, Argentina: Antropofagia.

Gudynas, E. (2009). Diez tesis urgentes sobre el nuevo extractivismo. Contextos y demandas bajo el progresismo sudamericano actual. En AA.VV., Extractivismo, politica y sociedad (pp. 187-224). Quito: CAAP/CLAES.

Harvey, D. (2004). El “nuevo" imperialismo: acumulación por desposesión. Socialist Register, 40, 99-129. Recuperado de http://biblioteca.clacso.edu.ar/clacso/se/20130702120830/harvey.pdf

Kay, C., y Pineda, M. (1998). ¿El fin de la reforma agraria en América Latina? El legado de la reforma agraria y el asunto no resuelto de la tierra. Revista Mexicana de Sociologia, 60(4), 63-98.

Larrañaga E., P., y Osores G., M. A. (2017). Catastro frutícola. Principales resultados. Región de Valparaíso /Julio 2017. Santiago de Chile: Oficina de Estudios y Políticas Agrarias/Centro de Información de Recursos Naturales.

Leff, E. (2004). La ecología política en América Latina: un campo de construcción. En H. Alimonda (comp.), Los tormentos de la materia. Aportes para una ecología politica latinoamericana (pp. 21-39). Buenos Aires: CLACSO.

Martínez-Alier, J. (1995). De la economia ecológica al ecologismo popular. Barcelona: Icaria.

Mayring, P. (2000). Qualitative Content Analysis. Forum Qualitative Sozialforschung / Forum: Qualitative Social Research, 1(2). Recuperado de http://nbn-resolving.de/urn:nbn:de:0114-fqs0002204

Moreano, M., Molina, F., y Bryant, R. (2017). Hacia una ecología política global: aportes desde el sur. En H. Alimonda, C. Toro Pérez y F. Martín (coord.), Ecología política latinoamericana: pensamiento crítico, diferencia latinoamericana y rearticulación epistémica (pp. 197-211). México: Universidad Autónoma Metropolitana.

Oszlak, O., y O’Donnell, G. (1995). Estado y políticas estatales en América Latina: hacia una estrategia de investigación. Redes, 2(4), 99-128. Recuperado de https://www.redalyc.org/pdf/907/90711285004.pdf

Ricouer, P. (2008). Hermenéutica y acción: de la hermenéutica del texto a la hermenéutica de la acción. Buenos Aires: Prometeo.

Sobreiro Filho, J. (2017). Instrumentos teóricos para analisar os movimentos socioespaciais e a perspectiva geográfica: conflitualidade, contentious politics; terrains of resistance, socio-spatial positionality e convergence spaces. Revista NERA, 20(39), 13-38.

Svampa, M. (2019). Las fronteras del neoextractivismo en América Latina. Conflictos socioambientales, giro ecoterritorial y nuevas dependencias. Guadalajara: CALAS. Recuperado de https://biblio.flacsoandes.edu.ec/li bros/digital/57523.pdf

Temper, L., del Bene, D., y Martinez-Alier, J. (2015). Mapping the frontiers and front lines of global environmental justice: the EJAtlas. Journal of Political Ecology, 22(1), 255-278. 
Teubal, M., y Palmisano, T (2012). Acumulación por desposesión: la colonialidad del poder en América Latina. En G. Massuh (ed.), Renunciar al bien común. Extractivismo y (pos)desarrollo en América Latina (pp. 131-156). Buenos Aires: Mardulce.

Tilly, C. (1978). From Mobilization to Revolution. Reading: Addison-Wesley.

Toledo López, V. (2011). Conflictos ambientales y territorio. En la búsqueda de una complementariedad teóricoconceptual. Estudios Socioterritoriales Revista de Geografia, julio-diciembre, 10, 155-176.

Walter. M. (2009). Conflictos ambientales, socioambientales, ecológico distributivos, de contenido ambiental... Reflexionando sobre enfoques y definiciones. Boletin ECOS, febrero-abril, 6, 2-9.

\section{OTRAS REFERENCIAS}

Comunidad de Crianceros El Manzano (31 de agosto de 2016). Comunicado público. Putaendo: Comunidad de Crianceros El Manzano. Putaendo Informa. Recuperado de https://kaosenlared.net/chile-crianceros-de-el-man zano-denuncian-amenazas-constantes-por-parte-de-la-compania-ganadera-tongoy/

Corporación de la Reforma Agraria (1968). Plan de área. San Felipe - Los Andes. Santiago de Chile: Corporación de la Reforma Agraria.

Corte Suprema de Justicia (04 de julio de 2019a). Fallo 38.495-2017. Santiago de Chile: Corte Suprema de Justicia.

Corte Suprema de Justicia (04 de julio de 2019b). Fallo 38.487-2017. Santiago de Chile: Corte Suprema de Justicia.

DGA (01 de febrero de 2018). Planilla Decretos zonas de escasez hídrica (2008 - 2018). Santiago de Chile: DGA. Recuperado de https://www.dga.cl/DGADocumentos/Decretos_zonas_escasez_historico.xls

Junta de Gobierno de la República (17 de diciembre de 1973). Decreto Ley $N^{\circ} 208$. Santiago de Chile: Diario Oficial de la República de Chile.

Junta de Gobierno de la República (13 de Agosto de 1981). Decreto Ley $N^{\circ} 1.122$. Santiago de Chile: Diario Oficial de la República de Chile.

Servicio Evaluación Ambiental (21 de octubre de 2008). Resolución de Clificación Ambiental (RCA). Valparaíso: Servicio de Evaluación Ambiental. Recuperado de https://infofirma.sea.gob.cl/DocumentosSEA/MostrarDoc umento?docId=66/fd/a9a7f5125a9f160685e0f1b66e954b52b9ca

Servicio Evaluación Ambiental (17 de marzo de 2020). Resolución Exenta $N^{o} 76$. Valparaíso: Servicio Evaluación Ambiental. Recuperado de https://infofirma.sea.gob.cl/DocumentosSEA/MostrarDocumento?docId=0d/98/ 91440778e47ef50c56e0b8b0f57ea60662b1 


\section{Entrevistas}

\begin{tabular}{|c|c|c|c|}
\hline Fecha & Cod. & Entrevistado/a & Lugar \\
\hline $19 / 7 / 2019$ & P01 & $\begin{array}{l}\text { Coordinador territorial senatorial para la Región de } \\
\text { Valparaíso }\end{array}$ & Valparaíso \\
\hline 9/9/2019 & P02 & Criancero y dirigente & San Felipe \\
\hline $9 / 9 / 2019$ & $\mathrm{P} 03$ & Coordinador territorial senatorial de Aconcagua & Las Coimas \\
\hline $2 / 12 / 2019$ & P04 & Criancero y guía de cabalgatas & Putaendo \\
\hline $3 / 12 / 2019$ & P05 & Comerciante y miembro de la agrupación Putraintú & Putaendo \\
\hline $3 / 12 / 2019$ & P06 & $\begin{array}{l}\text { Criancero, agricultor, guía de cabalgatas y trabajador de } \\
\text { Tongoy }\end{array}$ & Los Patos \\
\hline $3 / 12 / 2019$ & P07 & Criancero y guía de cabalgatas & Los Patos \\
\hline $3 / 12 / 2019$ & P08 & Ganadero, agricultor y presidente de canal & El Tártaro \\
\hline $4 / 12 / 2019$ & P09 & $\begin{array}{c}\text { Criancero y autoridad de la serranía La Victoria de } \\
\text { Piguchén }\end{array}$ & Piguchén \\
\hline $4 / 12 / 2019$ & P10 & Crianceros & Putaendo \\
\hline $4 / 12 / 2019$ & P11 & Técnicos PRODESAL & Putaendo \\
\hline $5 / 12 / 2019$ & $\mathrm{P} 12$ & $\begin{array}{l}\text { Pequeño minero y autoridad de la Asociación Minera de } \\
\text { Putaendo }\end{array}$ & Putaendo \\
\hline $5 / 12 / 2019$ & P13 & $\begin{array}{l}\text { Agricultores y miembros de la Junta de Vigilancia del Río } \\
\text { Putaendo }\end{array}$ & Putaendo \\
\hline $5 / 12 / 2019$ & P14 & Funcionario municipal (Ärea de Medio Ambiente) & Putaendo \\
\hline $6 / 12 / 2019$ & P15 & Contratista & Putaendo \\
\hline $6 / 12 / 2019$ & P16 & Autoridad de Agua Potable Rural & Guzmanes \\
\hline $7 / 12 / 2019$ & P17 & Ganadero y agricultor & La Orilla \\
\hline $7 / 12 / 2019$ & P18 & Criancera & La Orilla \\
\hline $9 / 12 / 2019$ & P19 & Repartidor de Agua de la Junta de Vigilancia & Sector Alto \\
\hline $9 / 12 / 2019$ & P20 & Agricultor $\mathrm{y}$ apicultor & Granalla \\
\hline 10/12/2019 & P21 & Agricultor & Quebrada Herrera \\
\hline 10/12/2019 & P22 & Agricultores, crianceros y médicos tradicionales & Piguchén \\
\hline 10/12/2019 & P23 & Funcionario municipal (Ärea de Patrimonio Ambiental) & Putaendo \\
\hline $11 / 12 / 2019$ & $\mathrm{P} 24$ & Miembro de la agrupación Putaendo Resiste & Putaendo \\
\hline $11 / 12 / 2019$ & $\mathrm{P} 25$ & Pequeño minero y miembro de la Coordinadora Tres Ríos & Putaendo \\
\hline
\end{tabular}

